\title{
Glycinebetaine Seed Priming Improved Osmotic and Salinity Tolerance in Turfgrasses
}

\author{
Qi Zhang' and Kevin Rue \\ Department of Plant Sciences, North Dakota State University, P.O. Box \\ 6050, Fargo, ND 58108
}

Additional index words. germination, seedling, mannitol, $\mathrm{NaCl}$

\begin{abstract}
Exogenous application of glycinebetaine (GB), an osmoprotectant, increases tolerance to stresses including salinity in various plants. Information on turfgrass, however, is limited. In this study, GB was used to prime turfgrass seeds to enhance salinity tolerance during germination and seedling growth stage when plants are more sensitive to stresses. Unprimed and primed (50, 100, 150, or $200 \mathrm{~mm}$ solution of GB or distilled water) seeds of perennial ryegrass (Lolium perenne $\mathrm{L}$.) (PR), tall fescue (Festuca arundinacea Schreb.) (TF), creeping bentgrass (Agrostis palustris Huds.) (CB), and kentucky bluegrass (Poa pratensis L.) (KB) were germinated in solutions of distilled water, mannitol (causing osmotic stress only), or $\mathrm{NaCl}$ (causing both osmotic and ionic stresses). Their osmotic potential $\left(\psi_{\mathrm{S}}\right)$ and salinity level were $-0.1 \mathrm{MPa}$ and $0.1 \mathrm{dS} \cdot \mathrm{m}^{-1}$ (no stress), -1.0 MPa and $0.1 \mathrm{dS} \cdot \mathrm{m}^{-1}$ (moderate osmotic stress), and $-1.0 \mathrm{MPa}$ and $14.6 \mathrm{dS} \cdot \mathrm{m}^{-1}$ (moderate osmotic and ionic stresses), respectively. Seeds primed with GB showed a higher germination rate $(11.0 \%$ to $13.9 \%$ increase) and seedling growth (19.3\% to $\mathbf{2 0 . 7 \%}$ increase) in mannitol or $\mathrm{NaCl}$ solution than in distilled water. Different turf species showed different responses to osmotic and ionic stresses. No differences in germination and seedling growth of PR, TF, and KB were observed between mannitol and $\mathrm{NaCl}$ treatments, indicating that osmotic stress appeared to more critical than ionic stress under saline conditions. For $\mathbf{C B}$, the seed germination rate and seedling growth were lower $(19.3 \%$ to $44.2 \%$ reduction) in $\mathrm{NaCl}$ than in mannitol, showing an accumulative effect of both osmotic and ionic stresses under saline conditions.
\end{abstract}

Salinity is a major limiting factor in turfgrass management in arid and semiarid regions (Carrow and Duncan, 1998). Salinity inhibits turfgrass growth and development, resulting in poor turfgrass stands and reduced aesthetic and playable functions. Germination and seedling growth are more sensitive to salt stress than vegetative growth because of salt accumulations in surface soil resulting from evaporation, percolation, and capillary rise of water (Almansouri et al., 2001). Impact of salinity on plants is often caused by salt-induced osmotic stress and ion toxicity and imbalance (Marcum, 2007). The importance of each of the two components, however, may differ among plant species or cultivars (Almansouri et al., 2001). Higher seed germination and seedling growth rates were observed under osmotic stress compared with salt stress in cotton (Gossypium hirsutum L.) (Heikal and Shaddad, 1982) and Brassica species (Huang and Redmann, 1995). In contrast, two Atriplex species showed higher germination and seedling growth under saline conditions than under

\footnotetext{
Received for publication 12 Apr. 2012. Accepted for publication 11 June 2012.

This research was supported in part by Hatch Project ND01540.

We thank Drs. A. Zuk and R. Smith for their valuable suggestions and comments when we were preparing the manuscript.

${ }^{1}$ To whom reprint requests should be addressed; e-mail qi.zhang.1@ndsu.edu.
}

osmotic stress (Katembe et al., 1998). To the best of our knowledge, no study has been conducted to compare the individual osmotic stress with ionic stress induced by salinity during seed germination and seedling growth in turfgrasses.

In response to environmental stresses such as salinity, drought, and freezing, plants deploy a diversity of mechanisms to protect themselves. One of the mechanisms is to accumulate osmoprotectants such as GB to keep the osmotic balance in cells and help plants survive extreme osmotic stress. Glycinebetaine accumulation has been widely documented in plants, including sugar beet (Beta vulgaris L.) and barley (Hordeum vulgare L.) (Ashraf and Foolad, 2007). Introduction of genes regulating the GB synthesis pathway in nonor low-GB-accumulating plants has shown enhanced stress tolerance (Ashraf and Foolad, 2007; Sakamoto and Murata, 1999).

Seed priming is an effective technique for rapid and uniform seed germination (Farooq et al., 2006). Seed priming can be achieved by various methods, all involving seed hydration during which embryo is pre-enlarged; therefore, germination rate may be enhanced (Austin et al., 1969; Gray and Steckel, 1977). Osmoconditioning is a special type of seed priming in which seeds are hydrated in aerated solutions with low water potential such as GB (Bradford, 1986; Bray, 1995). Improved performance was observed in GB primed rice (Oryza sativa L.) and canola (Brassica napus L.) seeds under suboptimal temperatures and salinity (Athar et al., 2009; Basra et al., 2005). Although the effect of GB seed priming on enhancing stress tolerance has been extensively studied in crop species, information on turfgrass is lacking.

The objectives of this study were to compare the effects of osmotic stress and ionic stress on seed germination and seedling growth in four cool-season turfgrass species and determine if GB seed priming enhances both osmotic and salinity tolerance in turfgrasses.

\section{Materials and Methods}

Seed treatment. Four turfgrasses with contrasting salinity tolerance were included in this study: PR and TF rate as moderately tolerant, $\mathrm{CB}$ moderately sensitive, and $\mathrm{KB}$ sensitive to saline conditions (Harivandi et al., 1992). Seeds of each turfgrass species were primed following the method of Farooq et al. (2006). Seeds were briefly soaked in continuously aerated distilled water or $50,100,150$, and $200 \mathrm{~mm}$ of $\mathrm{GB}$ for $24 \mathrm{~h}$ at $25 \pm 2{ }^{\circ} \mathrm{C}$. The ratio of seed weight to solution volume was 1:5 to ensure adequate quantity of solution for absorption. Seeds were then rinsed three times with distilled water and air-dried to the original weight in a laminar-flow hood $(\approx 12 \mathrm{~h})$ in the dark. Unprimed seeds were also included in the experiment.

Seed germination and seedling growth. Thirty unprimed or primed seeds of each grass were placed on a germination paper (Anchor Paper Company, St. Paul, MN) in a $100 \times$ $15-\mathrm{mm}$ petri dish. Before planting, the germination paper was moistened with $7 \mathrm{~mL}$ of distilled water, mannitol $(300 \mathrm{~mm})$, or $\mathrm{NaCl}$ $\left(10 \mathrm{~g} \cdot \mathrm{L}^{-1}\right)$. The $\mathrm{NaCl}$ concentration was selected to be within the salinity range causing $50 \%$ germination reduction in $\mathrm{TF}$, $\mathrm{CB}$, and KB (Zhang et al., 2011). Mannitol was used to induce osmotic stress because it can penetrate in plant cell as $\mathrm{NaCl}$, causing decreased internal $\psi_{\mathrm{S}}$ (Almansouri et al., 2001). The salinity level of distilled water, mannitol, and $\mathrm{NaCl}$ was $0.1,0.1$, and 14.6 $\mathrm{dS} \cdot \mathrm{m}^{-1}$, respectively, measured with an electrical conductivity meter (Model 1054; VWR International LLC, West Chester, PA). The $\psi_{\mathrm{S}}$ of the solution was determined with a WP4 dewpoint potentiameter (Decagon Devices, Inc., Pullman, WA). The $\psi_{\mathrm{S}}$ of distilled water, mannitol, and $\mathrm{NaCl}$ was $-0.1,-1.0$, and $-1.0 \mathrm{MPa}$, respectively. Petri dishes were then sealed with parafilm and placed in a culture room at $25 \pm 2{ }^{\circ} \mathrm{C}$ under fluorescent light $\left(36 \mu \mathrm{mol} \cdot \mathrm{s}^{-1} \cdot \mathrm{m}^{-2}\right)$ with a $16 / 8$-h (light/ dark) photoperiod. Seed germination, defined as an emerged shoot visible under $2 \times$ magnification (McCarty and Dudeck, 1993), was recorded three times weekly. Final germination rate, presenting total germination rate over a period of time, and daily germination rate, and presenting germination speed were calculated following the procedure of Zhang et al. (2011). Fresh weight of plant tissues was recorded when they were harvested at $28 \mathrm{~d}$. All plant tissues were dried at $65^{\circ} \mathrm{C}$ for $48 \mathrm{~h}$ and the absolute water content (fresh weight dry weight), an indicator of leaf area (Hughes 
et al., 1970), was calculated. The experiment was arranged in a three (germination solutions) $\times$ four (turfgrass species) $\times$ six (seed priming) factorial deign with three replicates (three petri dishes). To avoid differences in seed size and seedling vigor in different turfgrass species, data were standardized as the percentage of control (unprimed seeds germinated in distilled water) within each species (Zhang et al., 2011). All data were subjected to PROC GLM (SAS Institute Inc., Cary, NC) and means were separated with Fisher's protected least significant difference at $P \leq 0.05$.

\section{Results}

Effects of osmotic and salinity stresses on seed germination. Interactions did not occur among germination solution $\times$ turfgrass species $\times$ seed priming in final germination rate (Table 1). Only one two-way interaction (germination solution $\times$ turfgrass species) was observed in the final germination rate. All grasses showed a similar level of final germination rate in distilled water, $100.5 \%$ of control (unprimed seeds germinated in distilled water), when data were pooled across all seed priming treatments (Fig. 1A). In the mannitol treatment, final germination rate of the four grasses decreased in the following order: $\mathrm{PR}>\mathrm{TF}>\mathrm{CB}>\mathrm{KB}$. The same ranking of grass tolerance was observed in final germination rate in the $\mathrm{NaCl}$ treatment. Final germination rates of $\mathrm{PR}, \mathrm{TF}$, and $\mathrm{KB}$ were at a similar level between mannitol and $\mathrm{NaCl}$, whereas final germination rate of $\mathrm{CB}$ in the $\mathrm{NaCl}$ treatment (37.6\% of control) was lower than in mannitol (51.6\% of control).

An interaction between the germination solution and turfgrass species in daily germination rate was observed (Table 1). The average daily germination rate across grasses was $104.5 \%$ of control when germinated in distilled water (Fig. 1B). Perennial ryegrass had the highest daily germination rate when germinated in mannitol followed by TF, CB, and finally $\mathrm{KB}$, which had the lowest daily germination rate. A similar ranking of daily germination rate was observed when seeds were germinated in the $\mathrm{NaCl}$ solution except that $\mathrm{CB}$ and $\mathrm{KB}$ showed a similar level of daily germination rate (average $=18.9 \%$ of control).

Effects of osmotic and salinity stresses on seedling growth. An interaction occurred between the germination solution and turfgrass species in seedling responses (Table 1). In distilled water, the fresh weight of PR was the highest, $14.1 \%$ higher than those of TF and $\mathrm{CB}$. The fresh weight of TF was $13.3 \%$ lower than that of the other three grass species (Fig. 2). A significant difference in fresh weight was observed among the four grass species. The fresh weight decreased in the following order: $\mathrm{PR}>\mathrm{TF}>\mathrm{CB}>\mathrm{KB}$ after germination in mannitol and $\mathrm{NaCl}$, except that there was not a significant decrease between $\mathrm{CB}$ and $\mathrm{KB}$ in the $\mathrm{NaCl}$ solution. Within each species, seedling fresh weight was higher in distilled water (range, 96.7\% to $116.4 \%$ of control) compared with the mannitol (22.5\% to $91.5 \%$ of control) or $\mathrm{NaCl}$ treatments (20.1\% to $90.2 \%$ of control). No differences in seedling fresh weight were observed between the mannitol and $\mathrm{NaCl}$ treatments.

The changes in absolute water content across the grass species and solutions were similar to the fresh weight differences (Fig. 3). Absolute water content was the highest in seedlings grown in distilled water (average $=$

$108.5 \%$ of control) with no differences observed between the mannitol and $\mathrm{NaCl}$ treatments (averaged $62.1 \%$ and $44.7 \%$ of control, respectively). Perennial ryegrass seedlings grown in mannitol and $\mathrm{NaCl}$ had the highest absolute water content followed by TF, CB, and $\mathrm{KB}$ except in the $\mathrm{NaCl}$ treatment in which no differences were observed between $\mathrm{CB}$ and $\mathrm{KB}$. Among species grown in different solutions, absolute water content in distilled water

Table 1. Analysis of variance. ${ }^{z}$

\begin{tabular}{|c|c|c|c|c|}
\hline & \multicolumn{2}{|c|}{ Germination } & \multicolumn{2}{|c|}{ Seedling growth } \\
\hline & Final germination rate & Daily germination rate & Fresh wt & Absolute water content \\
\hline$\overline{\text { Solution (So) }}$ & $* * *$ & $* * *$ & $* * *$ & $* * *$ \\
\hline Species (Sp) & $* * *$ & $* * *$ & $* * *$ & $* * *$ \\
\hline Priming $(\mathrm{P})$ & $* * *$ & NS & $* * *$ & $* * *$ \\
\hline So $\times \mathrm{Sp}$ & $* * *$ & $* * *$ & $* * *$ & $* * *$ \\
\hline So $\times \mathrm{P}$ & NS & NS & NS & NS \\
\hline $\mathrm{Sp} \times \mathrm{P}$ & NS & NS & NS & NS \\
\hline So $\times \mathrm{Sp} \times \mathrm{P}$ & NS & NS & NS & NS \\
\hline
\end{tabular}

${ }^{\mathrm{z}}$ Data were presented as percent of control (unprimed seeds germinated in distilled water) within each species.

$*, * *, * * *$ represent significant differences at the probability level of $0.05,0.01$, and 0.001 level, respectively.

$\mathrm{NS}=$ nonsignificant differences at the probability level of 0.05 level.
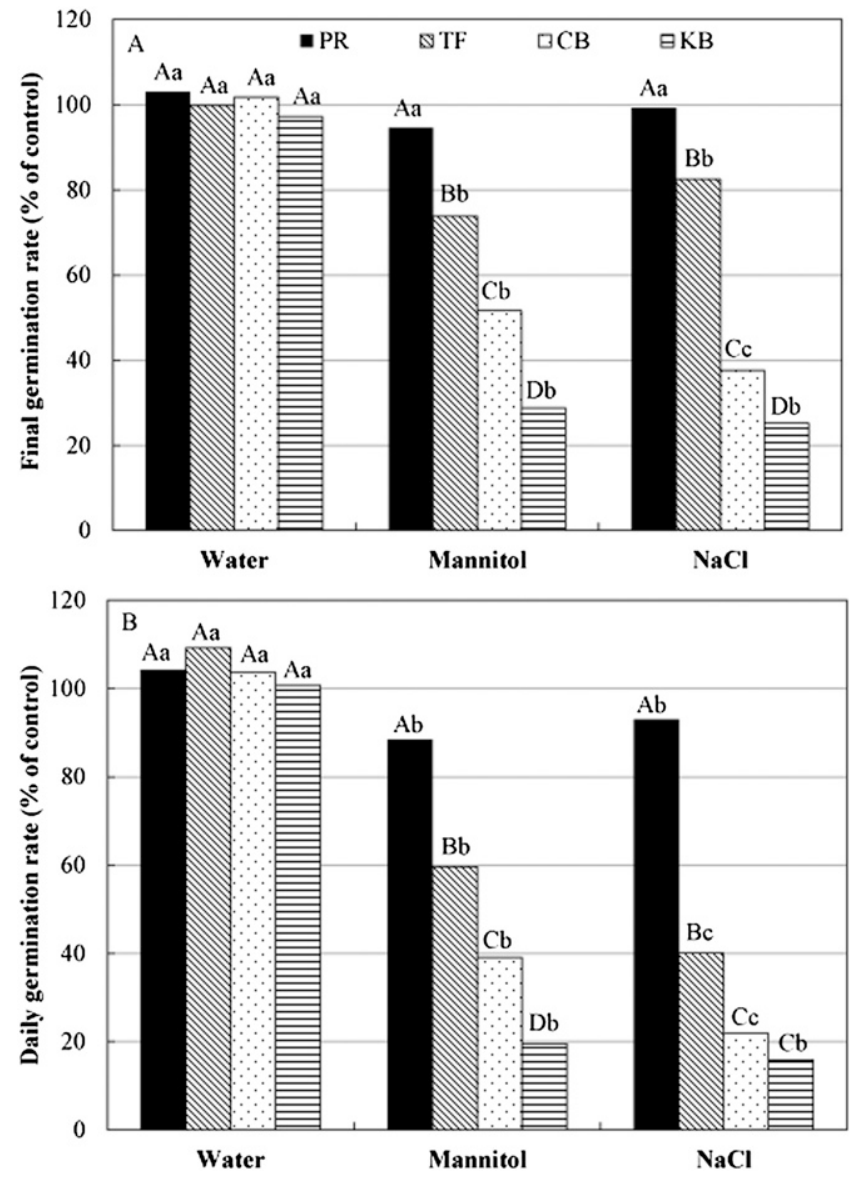

Fig. 1. Final germination rate (A) and daily germination rate $(\mathbf{B})$ in perennial ryegrass $(\mathrm{PR})$, tall fescue $(\mathrm{TF})$, creeping bentgrass (CB), and kentucky bluegrass (KB) in distilled water, mannitol, or $\mathrm{NaCl}$ solution. The osmotic potential $\left(\psi_{\mathrm{S}}\right)$ of distilled water, mannitol, and $\mathrm{NaCl}$ was $-0.1,-1.0$, and $-1.0 \mathrm{MPa}$, respectively. The salinity level of distilled water, mannitol, and $\mathrm{NaCl}$ was $0.1,0.1$, and $14.6 \mathrm{dS} \cdot \mathrm{m}^{-1}$, respectively. Data were presented as percent of control (unprimed seeds germinated in distilled water) within each species. Uppercase letters above bars indicated differences of turfgrass species under each germination solution at $P \leq 0.05$. Lowercase letters above bars indicated differences of germination solutions within turfgrass species at $P \leq 0.05$. 
m $\mathrm{PR}$

m TF

$\square \mathrm{CB}$

$\exists \mathrm{KB}$

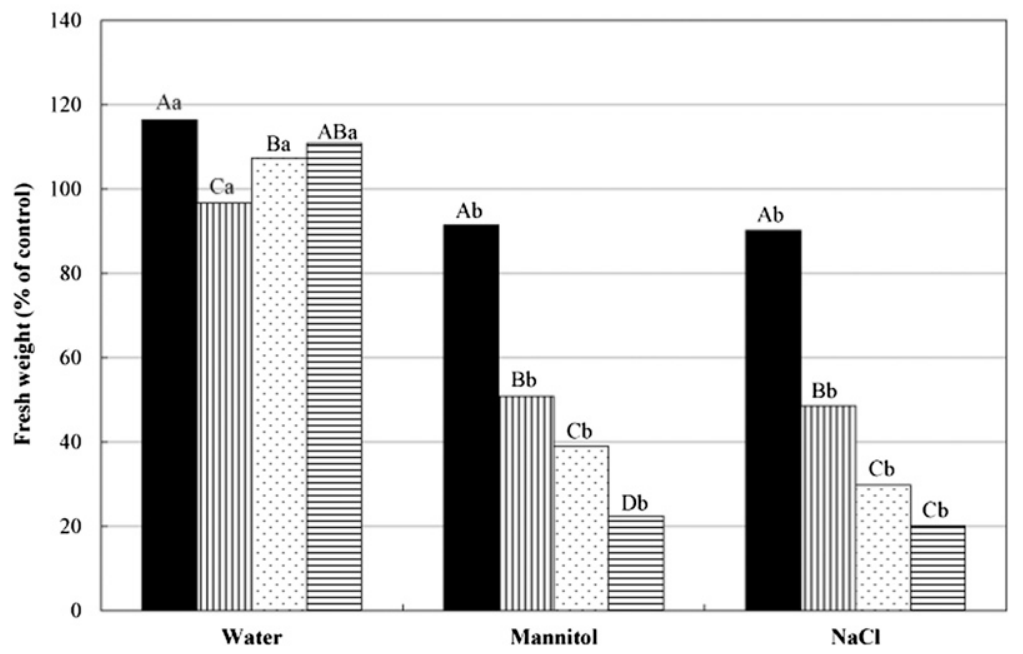

Fig. 2. Fresh weight of perennial ryegrass (PR), tall fescue (TF), creeping bentgrass (CB), and kentucky bluegrass $(\mathrm{KB})$ germinated in distilled water, mannitol, or $\mathrm{NaCl}$ solution. The osmotic potential $\left(\psi_{\mathrm{S}}\right)$ of distilled water, mannitol, and $\mathrm{NaCl}$ was $-0.1,-1.0$, and $-1.0 \mathrm{MPa}$, respectively. The salinity level of distilled water, mannitol, and $\mathrm{NaCl}$ was $0.1,0.1$, and $14.6 \mathrm{dS} \cdot \mathrm{m}^{-1}$, respectively. Data were presented as percent of control (unprimed seeds germinated in distilled water) within each species. Uppercase letters above bars indicated differences of turfgrass species under each germination solution at $P \leq$ 0.05. Lowercase letters above bars indicated differences of germination solutions within turfgrass species at $P \leq 0.05$.

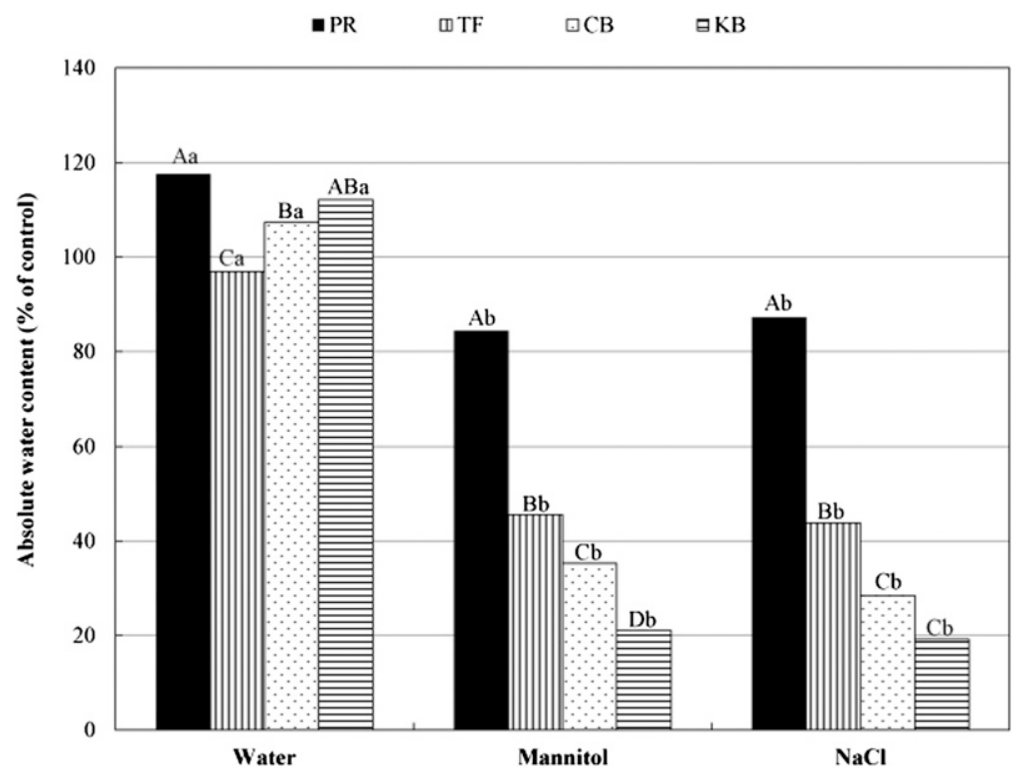

Fig. 3. Absolute water content of perennial ryegrass (PR), tall fescue (TF), creeping bentgrass (CB), and kentucky bluegrass $(\mathrm{KB})$ germinated in distilled water, mannitol, or $\mathrm{NaCl}$ solution. The osmotic potential $\left(\psi_{\mathrm{S}}\right)$ of distilled water, mannitol, and $\mathrm{NaCl}$ was $-0.1,-1.0$, and $-1.0 \mathrm{MPa}$, respectively. The salinity level of distilled water, mannitol, and $\mathrm{NaCl}$ was $0.1,0.1$, and $14.6 \mathrm{dS} \cdot \mathrm{m}^{-1}$, respectively. Data were presented as percent of control (unprimed seeds germinated in distilled water) within each species. Uppercase letters above bars indicated differences of turfgrass species under each germination solution at $P \leq 0.05$. Lowercase letters above bars indicated differences of germination solutions within turfgrass species at $P \leq 0.05$.

was higher than in mannitol and $\mathrm{NaCl}$. No differences occurred between the mannitol and $\mathrm{NaCl}$ treatments.

Effect of seed priming with glycinebetaine on seed germination and seeding growth. Seed priming with GB significantly improved final germination rate. The average final germination rate of the four GB treatments was $77.0 \%$ of control, $11.2 \%$ higher than that of unprimed treatment (Table 2). The concentration of GB did not significantly affect final germination rate; however, $100 \mathrm{~mm} \mathrm{~GB}$ resulted in the highest final germination rate (79.7\% of control). No significant differences were observed in daily germination rate among seed priming treatments. Seed priming with GB significantly increased seedling fresh weight and absolute water content. The average fresh weight of GB-primed seedlings was $71.4 \%$ of control, which was $19.3 \%$ higher than the unprimed seeds and $6.8 \%$ higher than the distilled water-primed treatment. Seed priming with GB significantly increased absolute water content in seedlings with an increase of $20.7 \%$ and $7.3 \%$ in the unprimed and distilled water-primed seedlings, respectively.

\section{Discussion}

Plants are exposed to various abiotic stresses continually but are more susceptible during the germination and seedling growth stages. Salinity-induced inhibition of germination and seedling growth are the result of osmotic stress and ionic stress. It is not clear if the two components of salinity stress act independently or together. Comparing the stress response of plants to the same level of iso-osmotic pressure caused by either mannitol or $\mathrm{NaCl}$ may help address this question. In general, seed germination and seedling vigor were reduced under osmotic (i.e., mannitol) and/or saline (i.e., $\mathrm{NaCl}$ ) conditions; however, the level of reduction varied among the type of stresses (osmotic, ionic) and within species. For example, mannitol and $\mathrm{NaCl}$ inhibited seed germination and seedling growth at the same level in PR and KB (Figs. 1-3), suggesting that osmotic stress plays a more important role than ionic stress in PR and $\mathrm{KB}$ under saline conditions. However, in $\mathrm{CB}, \mathrm{NaCl}$ caused a significant reduction in final germination rate and daily germination rate than mannitol (Fig. 1) and the seedling growth also showed a greater decrease in $\mathrm{NaCl}$ than in the mannitol $(\approx 10 \%$ decrease) (Figs. 2 and 3). This may indicate that osmotic and ionic stresses accumulatively affected seed germination and seedling growth of $\mathrm{CB}$. For TF, daily germination rate was the only parameter that showed a difference between osmotic and salinity stresses; therefore, TF may perform the same as $\mathrm{PR}$ and $\mathrm{KB}$ under salinity stress.

Osmotic and salinity tolerance differ in plant genotypes. In this study, osmotic and salinity tolerance among the four turfgrasses decreased in the following order: $\mathrm{PR}>\mathrm{TF}>$ $\mathrm{CB} \geq \mathrm{KB}$. Harivandi et al. (1992) reported a similar ranking of salinity tolerance in these grass species. However, Beard (1973) showed a different ranking of drought tolerance among the grasses used in this study, in which TF displayed good drought tolerance followed by $\mathrm{PR}$ and $\mathrm{KB}$ (medium) and $\mathrm{CB}$ (poor). The discrepancy between our study and the previous findings might be the result of the different cultivars evaluated in the studies or differences in growth stages. Because salinity tolerances vary during plant growth stages (Wang and Zhang, 2011; Zhang et al., 2012), we speculate that drought tolerance may also vary in growth stages as well. Unfortunately, growth stage was not defined by Beard (1973).

Exogenous application of GB helps enhance stress tolerance (Ashraf and Foolad, 2007). High tolerance in GB-primed plants may contribute to cellular osmotic adjustment, protection of membrane integrity, stabilization 
Table 2. Final germination rate, daily germination rate, fresh weight, and absolute water content in unprimed and primed [with distilled water or glycinebetaine (GB)] turfgrasses.

\begin{tabular}{|c|c|c|c|c|}
\hline \multirow[b]{2}{*}{ Seed priming } & \multicolumn{2}{|c|}{ Germination $^{z}$} & \multicolumn{2}{|r|}{ Seedling vigor ${ }^{z}$} \\
\hline & Final germination rate & Daily germination rate & Fresh wt & Absolute water content \\
\hline Unprimed & $69.2 \mathrm{c}^{\mathrm{y}}$ & $60.3 \mathrm{a}$ & $59.8 \mathrm{~b}$ & $57.5 \mathrm{~b}$ \\
\hline Distilled water & $70.5 \mathrm{bc}$ & $62.4 \mathrm{a}$ & $66.8 \mathrm{ab}$ & $64.7 \mathrm{ab}$ \\
\hline GB $50 \mathrm{~mm}$ & $75.1 \mathrm{ab}$ & $68.8 \mathrm{a}$ & $68.1 \mathrm{a}$ & $66.1 \mathrm{a}$ \\
\hline GB $100 \mathrm{~mm}$ & $79.7 \mathrm{a}$ & $71.4 \mathrm{a}$ & $74.1 \mathrm{a}$ & $71.9 \mathrm{a}$ \\
\hline GB $150 \mathrm{~mm}$ & $78.6 \mathrm{a}$ & $66.9 \mathrm{a}$ & $73.5 \mathrm{a}$ & $71.8 \mathrm{a}$ \\
\hline GB $200 \mathrm{~mm}$ & $74.5 \mathrm{abc}$ & $67.7 \mathrm{a}$ & $69.7 \mathrm{a}$ & $67.9 \mathrm{a}$ \\
\hline
\end{tabular}

${ }^{\mathrm{z}}$ Data were presented as percent of control (unprimed seeds germinated in distilled water) within each species.

${ }^{\mathrm{y}}$ Means followed by the same letter in each column are not significant at the probability level of 0.05 level.

of antioxidant enzymes that scavenge reactive oxygen species, or GB may play an indirect role in signal transduction during stress (Ashraf and Foolad, 2007; Chen and Murata, 2008). GB-primed seeds showed higher final germination rate, fresh weight, and absolute water content than unprimed seeds across the germination solutions and turfgrass species with the best results observed at $100 \mathrm{~mm}$ in this study (Table 2).

In conclusion, PR appears to be the most osmotic- and salt-tolerant species during the seed germination and seedling growth stages followed by TF and $\mathrm{CB}$ with $\mathrm{KB}$ being the most sensitive to such stresses. Seed priming with GB improved osmotic and salinity tolerance in turfgrasses, resulting in enhanced seed germination and seedling growth under the salinity stress.

\section{Literature Cited}

Almansouri, M., J.M. Kinet, and S. Lutts. 2001. Effect of salt and osmotic stresses on germination in durum wheat (Triticum durum Desf.). Plant Soil 231:243-254.

Ashraf, M. and M.R. Foolad. 2007. Roles of glycinebetaine and proline in improving plant abiotic stress resistance. Environ. Exp. Bot. $59: 206-216$
Athar, H., M. Ashraf, A. Wahid, and A. Jamil. 2009. Inducing salt tolerance in canola (Brassica napus L.) by exogenous application of glycinebetaine and proline: Response at the initial growth stages. Pak. J. Bot. 41:1311-1319.

Austin, R.B., P.C. Longden, and J. Hutchison. 1969. Some effects of 'hardening' carrot seed. Ann. Bot. (Lond.) 33:883-895.

Basra, S.M.A., M. Farooq, and R. Tabassum. 2005 Physiological and biochemical aspects of seed vigor enhancement treatments in fine rice (Oryza sativa L.). Seed Sci. Technol. 33:623-628.

Beard, J.B. 1973. Turfgrass: Science and culture. Prentice Hall, Englewood Cliffs, NJ.

Bradford, K.J. 1986. Manipulation of seed water relations via osmotic priming to improve germination under stress conditions. Horts. Sci. 21:1105-1112.

Bray, C.M. 1995. Biochemical process during the osmopriming of seeds, p. 767-789. In: Kigel, J. and G. Galili (eds.). Seeds development and germination. Marcel Dekker, New York, NY, Basel, Switzerland, Hong Hong.

Carrow, R.N. and R.R. Duncan. 1998. Salt-affected turfgrass sites: Assessment and management. Sleeping Bear Press, Inc., Chelsea, MI.

Chen, T.H.H. and N. Murata. 2008. Glycinebetaine: An effective protectant against abiotic stress in plants. Trends Plant Sci. 13:499-505.

Farooq, M., S.M.A. Basra, and K. Hafeez. 2006. Seed invigoration by osmohardening in coarse and fine rice. Seed Sci. Technol. 34:181-187.
Gray, D. and J.R.A. Steckel. 1977. Effects of presowing treatments on the germination and establishment of parsnips. J. Hort. Sci. Biotechnol. 52:525-534.

Harivandi, M.A., J.D. Butler, and L. Wu. 1992. Salinity and turfgrass culture, p. 207-229. In: Waddington, D.V., R.N. Carrow, and R.C. Shearman (eds.). Turfgrass. Agron. Mono. 32. ASA, CSSA, and SSSA, Madison, WI.

Heikal, M.M.D. and M.A. Shaddad. 1982. Alleviation of osmotic stress on seed germination and seedling growth of cotton, pea and wheat by proline. Phyton 22:275-287.

Huang, J. and R.E. Redmann. 1995. Salt tolerance of Hordeum and Brassica species during germination and early seedling growth. Can. J. Plant Sci. 75:815-819.

Hughes, A.P., K.E. Cockshull, and O.V.S. Heath. 1970. Leaf area and absolute leaf water content. Ann. Bot. (Lond.) 34:259-265.

Katembe, W.J., I.A. Ungar, and J.P. Mitchell. 1998. Effect of salinity on germination and seedling growth of two Atriplex species (Chenopodiaceae). Ann. Bot. (Lond.) 82:167-175.

Marcum. 2007. Physiological adaptations of turfgrasses to salinity stress. In: Pessarakli, M. (ed.). Handbook of turfgrass management and physiology. Taylor Francis Group, LLC, Boca Raton, FL.

McCarty, L.B. and A.E. Dudeck. 1993. Salinity effects on bentgrass germination. HortScience 28:15-17.

Sakamoto, A. and N. Murata. 1999. Genetic engineering of glycinebetaine synthesis in plants: Current status and implications for enhancement of stress tolerance. J. Expt. Bot. 51:81-88.

Wang, S. and Q. Zhang. 2011. Evaluation of salinity tolerance of prairie junegrass, a potential low-maintenance turfgrass species. HortScience 46:1038-1043.

Zhang, Q., K. Rue, and S. Wang. 2012. Salinity effect on seed germination and growth of two warm-season native grass species. HortScience 47:527-530.

Zhang, Q., S. Wang, and K. Rue. 2011. Salinity tolerance of 12 turfgrasses in three germination media. HortScience 46:651-654. 